\title{
The Merit-Order Effect of Load-Shifting: An Estimate for the Spanish Market
}

\author{
Juan M. ROLDAN FERNANDEZ ${ }^{1 *}$, Manuel BURGOS PAYAN ${ }^{2}$, \\ Jesus M. RIQUELME SANTOS ${ }^{3}$ \\ ${ }^{1-3}$ Department of Electrical Engineering, Universidad de Sevilla, \\ Camino de los Descubrimientos s/n, Seville, 41092, Spain
}

\begin{abstract}
Renewable producers can offer selling bids with very low marginal cost since they are not obliged to include on any cost related to the use of energy from the wind or sun. Accordingly, when the Market Operator integrates a renewable bid in the merit-order generation curve, all the generators based on conventional technologies, with higher marginal cost due to the cost of fuels, are displaced to the right. The right-shifting of the merit-order generation curve leads to a lower clearing price, a small increment of the traded energy (almost inelastic demand curve), and a reduction of the total cost of the energy traded in the wholesale market. This is the key mechanism of the well-known merit-order effect of renewables. Load-shifting (demand-side management) plans are expected to yield a reduction of the cost of the traded energy for the customers, since the cost-saving due to the energy eschewed at peak hours would be greater than the extra cost due to the increased demand at off-peak hours. This work will show that the main effects of load-shifting on the market are qualitatively similar to that of renewables, which exemplify the existence a "merit-order effect of load-shifting". To analyse the characteristics of the merit-order effect of load-shifting, a simplified model has been developed, based on the displacement of the generation and demand curves. A set of scenarios has been generated in order to quantify the main effects on the Spanish/Iberian market for 2015.
\end{abstract}

Keywords - Demand-side management; electricity markets; load-shifting; merit-order effect; renewable energy.

\begin{tabular}{|lll|}
\hline Nomenclature & & \\
$W$ & Traded energy & MWh \\
$p$ & Marginal price & $€ / \mathrm{MWh}$ \\
$C$ & Cost of the traded energy & $€$ \\
$m$ & Slope of the generation and demand curves & $€ / \mathrm{MWh}^{2}$ \\
Sub-index & & \\
$\mathrm{G}$ & Generation & \\
$\mathrm{D}$ & Demand & \\
$\mathrm{L}$ & Linearized & \\
$\mathrm{R}$ & Renewable & \\
$\mathrm{S}$ & Load-Shifting & \\
\hline
\end{tabular}

*Corresponding author.

E-mail address: jmroldan@us.es 


\begin{tabular}{|ll|}
\hline $\mathrm{i}$ & Initial \\
$\mathrm{s}$ & Simple \\
$\mathrm{p}$ & Peak \\
$\mathrm{v}$ & Off-peak or valley \\
\hline
\end{tabular}

\section{INTRODUCTION}

The Market Operator, from the selling and buying bids submitted by the generation and demand agents, creates a merit-order dispatch for every hour of the day ahead by placing the supply bids in order of ascending price and demand bids in descending order. By simplifying the complexity of the welfare optimization process, the Market Operator then establishes the clearing point as the intersection of the merit-order generation and demand curves.

Renewable generators produce their energy from natural resources, such as the wind or the sun, and therefore produce electric power with very low operating costs. Accordingly, they can submit selling bids with exceptionally low, even null prices. The liberalized market rules currently in force require the Market Operator to provide the merit-order generation curve by arranging the sale bids in order of increasing sale price. Therefore, the Market Operator has to place the supply bids from new renewable generators at the very first step of the ordered generation curve, due to their low price. As a consequence, the comparatively more expensive supply bids from the conventional generators are pushed to the right-hand side of the ordered generation curve. This right-shifting of the conventional generators combined with the characteristic lack of elasticity in demand produces a noticeable reduction of the clearing price, since the new clearing price is then set with a cheaper generator. In addition, it is likely that this new marginal generation unit will produce energy with less $\mathrm{CO}_{2}$ emissions.

It can be observed that the integration of renewables in the wholesale market prompts a shift of the operating point of the market towards a lower clearing price, a small increment of the traded energy and, as a consequence, a reduction of the total cost of the energy traded on the wholesale market. This constitutes the main mechanism, and its main effects, on the market of the very well-known merit-order effect of renewables.

The convergence of the promotion of load-shifting (demand-side management) by policy-makers and the interest of both industry and domestic consumers in reducing their energy bills is expected to yield a reduction of the cost of the energy, since the savings due to the amount of expensive energy eschewed at peak hours would be greater than the extra cost incurred by the increase of cheaper demand at off-peak hours. At peak hours, the reduction of demand bids would shift the merit-order demand curve to the left, which would in turn produce a simultaneous reduction of both the clearing price and the amount of traded energy. As a consequence of the left-shifting of the peak demand curve, the new clearing price is set by a cheaper and less pollutant generator. Conversely, the surplus demand at off-peak hours would right-shift the merit-order demand curve, thereby yielding a simultaneous growing of both the clearing price and the amount of traded energy. The right-shifting of the off-peak demand curve leads to a new higher clearing price which is set by a more expensive generator. Since at off-peak hours the traded energy and its prices are lower than at peak hours, the total cost of the traded energy in a load-shifting cycle would also diminish. In addition, it is likely that the new generation units integrated at off-peak hours are less pollutant than the avoided units at peak hours. 
It can be observed that the parallelism of the effects on the market from the integration of renewables and load-shifting demonstrates the existence of what could be called the merit-order effect of the load-shifting.

\subsection{Renewable Generation and Load-shifting: A Short Review}

The topic of merit-order effect of renewables has been broadly addressed in literature. Probably the first reference to the merit-order effect can be found in [1], where the cost of the German feed-in support of electricity generation from renewables was compared with the reduction of the cost of the energy traded in the market. The results for the year 2006 demonstrated that the cost saving in the German market due to the merit-order effect was larger than the support payments for renewables. The case of wind generation in Spain for the period 2005-2007 is considered in [2], showing that the renewables support scheme (charged to the final consumer), results in a net reduction in the retail electricity price. The case of renewables in Spain for the period 2008-2011 is considered in [3], and for the period 2008-2012 is analysed in [4], reaching similar conclusions.

The feedback on electricity consumption is analysed in [5] concluding that feedback improves the effectiveness of other information and advice in achieving better understanding and control of energy use. A strategy for a $100 \%$ renewable energy supply system for Latvia by the year 2050 is analysed in [6].

In [7], the question of to what extent might smart meters improve the customer engagement in household energy management is considered, while in [8], [9] the evidence from more than ten of recent pilots, experiments and full-scale implementation of dynamic pricing of electricity was surveyed. The work finds conclusive evidence that households respond to higher prices by lowering usage although the magnitude of price response depends on several factors. A broad literature review of the effectiveness of energy feedback for conservation and peak demand is performed in [10]. Load-shifting is a basic tool of demand management which is also used outside the context of electric power. For example, a demand side management case study in a pellet production facility is presented in [11]. Efficiency is another management tool often related to load-shifting. A case study for household electricity consumption in Latvia considering the effect of growth of demand and energy efficiency due to the technological development is considered in [12].

In Spain, the methodology for the calculation of the Voluntary Price for the Small Consumer, a real-time price tariff for small domestic consumers, came into force in 2014. The implementation of this real-time pricing scenario, as a tool of demand response, and the transposition of Directive 27/2014/EU, on energy saving, as a driver to improve the efficiency of the home appliances (for domestic consumers) was addressed in [13].

Finally, the integration of renewable production and demand-side management, are compared in [14] for the case of Spain for the period 2008-2014. The results of that work showed that demand-side management can be favourable compared with renewables in terms of cost of the energy traded in the market and environmental sustainability.

\subsection{Objectives}

The purpose of this work is to analyse the characteristics of the merit-order effect of the load-shifting and carry out a comparison with the corresponding characteristics of the merit-order effect of renewables. To this end, first a simplified model, based on the linearization of the market around the clearing point, is used for exploration purposes. An appropriate set of empirical-based scenarios with load-shifting is then generated from 
historical information regarding the Market Operator (OMIE) for the year 2015, in order to quantify the main effects on the Spanish/Iberian market.

Following this introduction, the content of the paper is as follows. The Iberian-Spanish electricity market is first briefly surveyed and a qualitative model, based on the linearization of the market around the clearing point, is employed to verify certain conjectures regarding the expected effects of load-shifting and renewables on the wholesale market. The hourly merit-order generation and demand curves for 2015 are subsequently used as source data for the creation of feasible and credible scenarios of load-shifting. The foremost potential effects on the wholesale market are then quantified and analysed. The work concludes with the main findings of the analysis.

\section{SURVEY OF THE IbERIAN-SPANISH ELECTRICITY MARKET}

The joint European regional market for Spain and Portugal is organized and managed by OMIE (Operador del Mercado Iberico de la Energia), the Market Operator of the Iberian Energy Market. Since 2014, OMIE has been integrated in the European Multi-Regional Coupling (MRC), and its market-clearing regulation is subject to the rules of EUPHEMIA (EU + Pan-European Hybrid Electricity Market Integration Algorithm) [15].

The day-ahead market is composed of 24-hourly markets that are each cleared once a day. The purpose of the daily market is the scheduling of electricity transactions for the day ahead of which it is performed through the submittal of generation and demand bids by their respective market agents. Two kinds of bids are considered in the Iberian Electricity Market: simple and complex bids. Simple bids are only price and energy bids. Complex bids, allowed solely for generation units, are bids which include any of the following conditions: indivisibility of blocks of energy, minimum income, scheduled stops, and load gradient.

Once the market agents have submitted their supply and demand bids, the Market Operator (OMIE) provides, for every hour of the day ahead, a merit-order dispatch by ordering the supply bids in ascending price order and demand bids in descending order. In the first step, only the simple bids are considered for the creation of the merit-order generation and demand curves. The Market Operator then simply matches the clearing point at the intersection of the merit-order supply and demand curves. Subsequently, an iterative welfare optimization algorithm finds a new solution, by including the constraints of the generation complex bids. After completing the welfare optimization procedure by means of EUPHEMIA, the final clearing price and traded energy are set for each hour of the day ahead. Finally, the System Operator (REE - Red Electrica de España) validates the schedule of the units while considering the technical restrictions of the electrical system.

As often occurs in optimization problems, as restrictions increase, the optimal solution is impaired. In the case of the electricity market, the incorporation of the complex generation bids significantly increases the final clearing price and slightly reduces the traded energy. On being dispatched, the price to be received or paid by the market participants is set according to a uniform-price auction. Irrespective of their bids, the price that producers receive or that which demand units pay is set equal to the highest accepted supply bid: the so-called system marginal price. 


\section{Simplified ANALYSIS OF THE WHOLESALE EleCtRicity MARKeT}

As previously mentioned, a simplified model, based on the linearization of the market around the clearing point, will be used to foresight or conjecture the impact on the market of the integration of renewables and the performance of a load-shifting cycle.

Fig. 1 shows the cleared generation, $p_{\mathrm{G}}=p_{\mathrm{G}}(\mathrm{W})$, and demand, $p_{\mathrm{D}}=p_{\mathrm{D}}(\mathrm{W})$, curves for a peak hour (20:00 h) on a working day in winter (Tuesday, 10 February, 2015), retrieved from OMIE [16]. As can be observed, and by its own nature, the supply curve, $p_{\mathrm{G}}=p_{\mathrm{G}}(\mathrm{W})$, has a gentle positive slope, while the demand curve, $p_{\mathrm{D}}=p_{\mathrm{D}}(\mathrm{W})$, displays a very negative slope, characteristic of its lack of flexibility. If the supply and demand curves were continuous, not stepped, and $m_{\mathrm{G}}=\mathrm{d} p_{\mathrm{G}}(\mathrm{W}) / \mathrm{d} W>0$ and $m_{\mathrm{D}}=\mathrm{d} p_{\mathrm{D}}(\mathrm{W}) / \mathrm{d} W<<0$ were, respectively, the slopes of the supply and demand curves at the initial clearing point (A in Fig. 1), then both the supply and demand curves could be linearized, in the vicinity of the clearing point $\left(W_{\mathrm{i}}, p_{\mathrm{i}}\right)$, as:

$$
\begin{aligned}
& p_{\mathrm{G}}(W) \approx p_{\mathrm{GL}}(W)=p_{\mathrm{i}}+m_{\mathrm{G}} \cdot\left(W-W_{\mathrm{i}}\right)=p_{\mathrm{G} i}+m_{\mathrm{G}} \cdot W \\
& p_{\mathrm{D}}(W) \approx p_{\mathrm{DL}}(W)=p_{\mathrm{i}}+m_{\mathrm{D}} \cdot\left(W-W_{\mathrm{i}}\right)=p_{\mathrm{Di}}+m_{\mathrm{D}} \cdot W
\end{aligned}
$$

where the new constants are:

$$
\begin{gathered}
p_{\mathrm{Gi}}=p_{\mathrm{i}}-m_{\mathrm{G}} W_{\mathrm{i}} \\
p_{\mathrm{Di}}=p_{\mathrm{i}}-m_{\mathrm{D}} W_{\mathrm{i}} .
\end{gathered}
$$

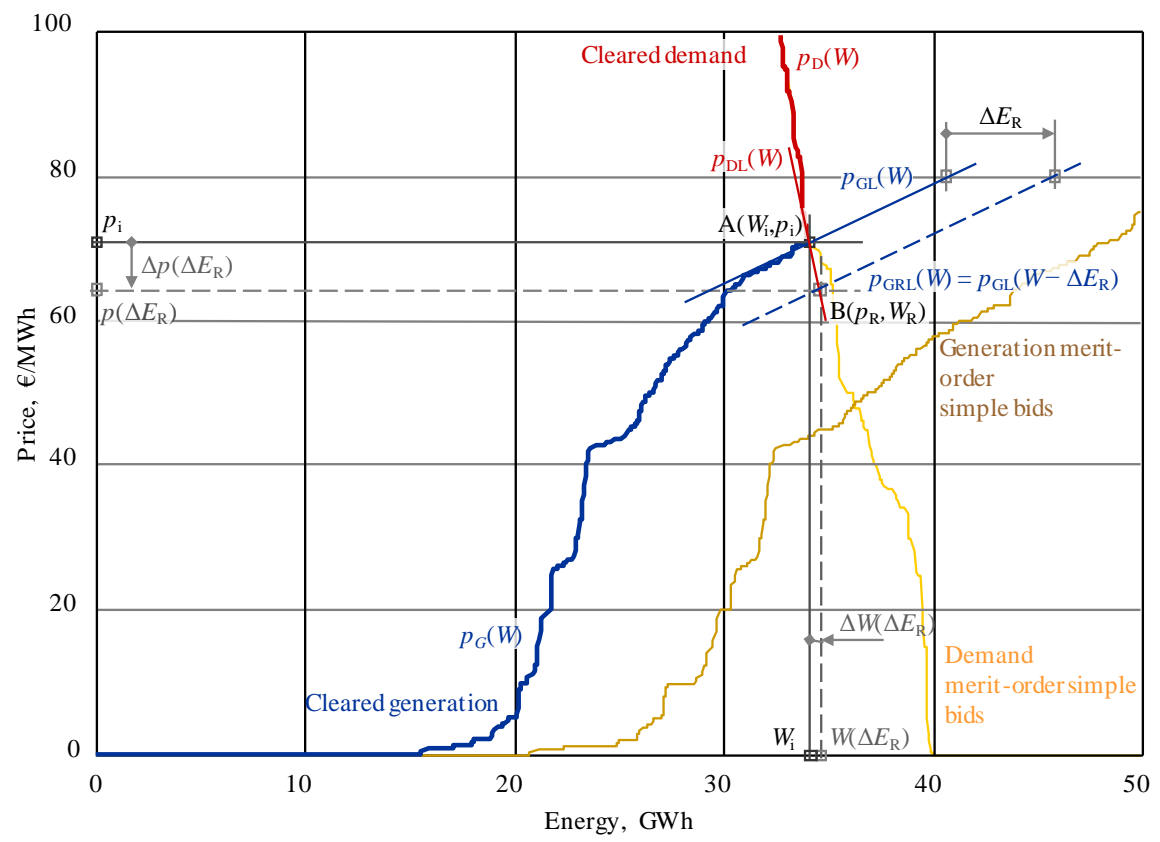

Fig. 1. Merit-order generation, $p_{\mathrm{G}}(\mathrm{W})$, and demand, $p_{\mathrm{D}}(\mathrm{W})$, curves for a peak hour on a working day in winter corresponding to the Iberian market [16]. Changes in the generation curve and market clearing point due to the integration of an amount of renewable bids, $\Delta E_{\mathrm{R}}$, at very low price. 
For the considered hour, the total income for the generators or the total cost for consumers derived from the energy traded at the wholesale market is:

$$
C_{\mathrm{i}}=W_{\mathrm{i}} p_{\mathrm{i}}
$$

With this linearized market model around the clearing point, the merit-order effect of renewable and load-shifting will be analysed and compared in order to obtain qualitative insight to the potential effects on the market.

Since the wholesale market is a marginal market, the clearing point is the only thing that matters. This means that although the linear approximations of the merit-order curves, $p_{\mathrm{G}}(\mathrm{W}) \approx p_{\mathrm{GL}}(\mathrm{W})$ and $p_{\mathrm{D}}(\mathrm{W}) \approx p_{\mathrm{DL}}(\mathrm{W})$, are completely different to the actual generation and demand curves, both sets of curves can lead to the same or very close clearing point.

Table 1 summarizes the data corresponding to a valley hour and a peak hour of a working day in winter (Tuesday, 10 February, 2015) in the wholesale Iberian market (OMIE) which will be applied in the following illustrative examples [16].

TABLE 1. DATA FOR THE LiNEARIZATION OF THE MARKET AROUND THE INITIAL CLEARING POINTS CORRESPONDING TO THE GENERATION AND DEMAND CURVES FOR PEAK AND VALLEY HOURS OF A WORKING DAY (TUESDAY, 10 FEBRUARY, 2015)

\begin{tabular}{lll}
\hline Magnitude & Valley hour $(04: 00 \mathrm{~h})$ & Peak hour $(20: 00 \mathrm{~h})$ \\
\hline Energy traded, $\mathrm{GWh}$ & $W_{\mathrm{iv}}=22.76$ & $W_{\mathrm{ip}}=34.18$ \\
Clearing price, $€ / \mathrm{MWh}$ & $p_{\mathrm{iv}}=43.06$ & $p_{\mathrm{ip}}=71.00$ \\
Generation slope, $€ / \mathrm{MWh}^{2}$ & $m_{\mathrm{Gv}}=2.9 \cdot 10^{-3}$ & $m_{\mathrm{Gp}}=1.4 \cdot 10^{-3}$ \\
Demand slope, $€ / \mathrm{MWh}^{2}$ & $m_{\mathrm{Dv}}=-7.2 \cdot 10^{-3}$ & $m_{\mathrm{Dp}}=-13.5 \cdot 10^{-3}$ \\
\hline
\end{tabular}

\subsection{Renewable Generation}

Current regulation of the Iberian-Spanish market requires the Market Operator to include all bids from renewable generators in the merit-order dispatch, on the condition that it causes no risk or technical difficulty for the safe operation of the system. As a consequence, the integration of new renewable generation bids, $\Delta E_{R}$, at a very low marginal price mainly results in a right-shifting of the initial merit-order generation curve, from the insertion point on. The linear approximation of this new supply curve, $p_{\mathrm{GR}}(\mathrm{W})$, is shown in Fig. 1 as a straight line parallel to the linear approximation of the primitive generation curve:

$$
p_{\mathrm{GR}}(W) \approx p_{\mathrm{GRL}}(W)=p_{\mathrm{GL}}\left(W-\Delta E_{\mathrm{R}}\right)=p_{\mathrm{i}}+m_{\mathrm{G}}\left(W-W_{\mathrm{i}}-\Delta E_{\mathrm{R}}\right)=p_{\mathrm{GRi}}+m_{\mathrm{G}} W,
$$

where

$$
p_{\mathrm{GRi}}=p_{\mathrm{i}}-m_{\mathrm{G}}\left(W_{\mathrm{i}}+\Delta E_{\mathrm{R}}\right) \text {. }
$$

With this linearized market model, the new clearing price and traded energy (B in Fig. 1) can be obtained by equalling the new generation curve with the demand curve.

Table 2 summarizes the expressions and results corresponding to the variation of the traded energy, clearing price, and cost of the traded energy derived from the integration of a certain amount of renewable energy bids, $\Delta E_{\mathrm{R}}$, at very low price. The results are based on the illustrative example in Table 1.

It should be noted that since the slope of the supply is less than the absolute value of that corresponding to the demand curve $\left(0<m_{\mathrm{G}}<\left|m_{\mathrm{D}}\right|\right)$, the resulting increment of traded energy 
is much lower than the increment of renewable energy bids integrated into the market. This means that when the Market Operator clears a certain amount of renewable energy bids, almost the same amount of energy bids from other more expensive and probably polluting production technologies are simultaneously left out. This technology replacement leads to a reduction of the clearing price which is approximately proportional to the amount of renewable energy integrated. This is the foundation of the well-known merit-order effect of renewable energy [1]-[4].

\section{TABLE 2. LINEARIZED MARKET MODEL ESTIMATION OF THE VARIATION OF THE TRADED ENERGY, PRICE, AND COST DERIVED FROM THE INTEGRATION OF AN AMOUNT OF RENEWABLE ENERGY BIDS}

\begin{tabular}{|c|c|c|c|c|}
\hline Magnitude & Expression & & Value & Eq. \\
\hline \multirow{2}{*}{ Relative variation of the traded energy } & $\Delta W\left(\Delta E_{\mathrm{R}}\right)$ & $m_{\mathrm{G}}$ & \multirow{2}{*}{0.09} & \multirow{2}{*}{$(8)$} \\
\hline & $\Delta E_{\mathrm{R}}$ & $\overline{m_{\mathrm{G}}-m_{\mathrm{D}}}$ & & \\
\hline \multirow{2}{*}{ Relative variation of the clearing price, $€ / \mathrm{MWh}^{2}$} & $\Delta p_{\mathrm{R}}\left(\Delta E_{\mathrm{R}}\right)$ & $m_{\mathrm{G}} m_{\mathrm{D}}<0$ & \multirow{2}{*}{$-1.27 \cdot 10^{-3}$} & \multirow{2}{*}{ (9) } \\
\hline & $\Delta E_{\mathrm{R}}$ & $m_{\mathrm{G}}-m_{\mathrm{D}}$ & & \\
\hline \multirow{2}{*}{ Relative variation of the cost of the energy traded, $€ / \mathrm{MWh}$} & $\Delta C\left(\Delta E_{\mathrm{R}}\right)$ & $\left(W_{\mathrm{i}} m_{\mathrm{D}}+p_{\mathrm{i}}\right) m_{\mathrm{G}}>0$ & \multirow{2}{*}{$-36.69 \cdot 10^{-3}$} & \multirow{2}{*}{ (10) } \\
\hline & $\Delta E_{\mathrm{R}}$ & $m_{\mathrm{G}}-m_{\mathrm{D}}$ & & \\
\hline
\end{tabular}

Therefore, the integration by the Market Operator of a certain quantity of renewable energy bids, $\Delta E_{\mathrm{R}}$, at very low price, yields a reduction of the cost of the traded energy in the market, which is approximately proportional to the amount of renewable energy integrated.

\subsection{Load-Shifting}

Consumers that apply for load-shifting programs expect to save in their electricity energy bills, due to the difference between the energy price at peak and off-peak hours [5], [7][10],[13],[14]. Nevertheless, when an important number of consumers shift an amount of energy from a peak hour to an off-peak hour, there is a resulting decrease in the price of the peak hour and an increase in the price of the off-peak hour, as can be observed in Fig. 2. This figure shows the merit-order generation, $p_{\mathrm{G}}(\mathrm{W})$, and demand, $p_{\mathrm{D}}(\mathrm{W})$, curves and matching clearing points for a valley $(04: 00 \mathrm{~h})$ and peak $(20: 00 \mathrm{~h})$ hours on a working day in winter (Tuesday, 10 February, 2015) corresponding to the wholesale Iberian market [16].

At peak hours, the curtailment of a certain amount of demand bids, $\Delta E_{\mathrm{Dp}}$, at very high marginal price, shift the initial demand curve to the left. The linear approximation of this new demand curve, $p_{\mathrm{DSp}}(\mathrm{W})$, is shown in Fig. 2 as a straight line parallel to the primitive linear approximation of the demand curve for the peak hour:

$$
p_{\mathrm{DSp}}(W) \approx p_{\mathrm{DLp}}\left(W+\Delta E_{\mathrm{Dp}}\right)=p_{\mathrm{ip}}+m_{\mathrm{Dp}}\left(W-W_{\mathrm{ip}}+\Delta E_{\mathrm{Dp}}\right)=p_{\mathrm{DSip}}+m_{\mathrm{Dp}} W,
$$

where

$$
p_{\mathrm{DSip}}=p_{\mathrm{ip}}-m_{\mathrm{Dp}}\left(W_{\mathrm{ip}}-\Delta E_{\mathrm{Dp}}\right)
$$




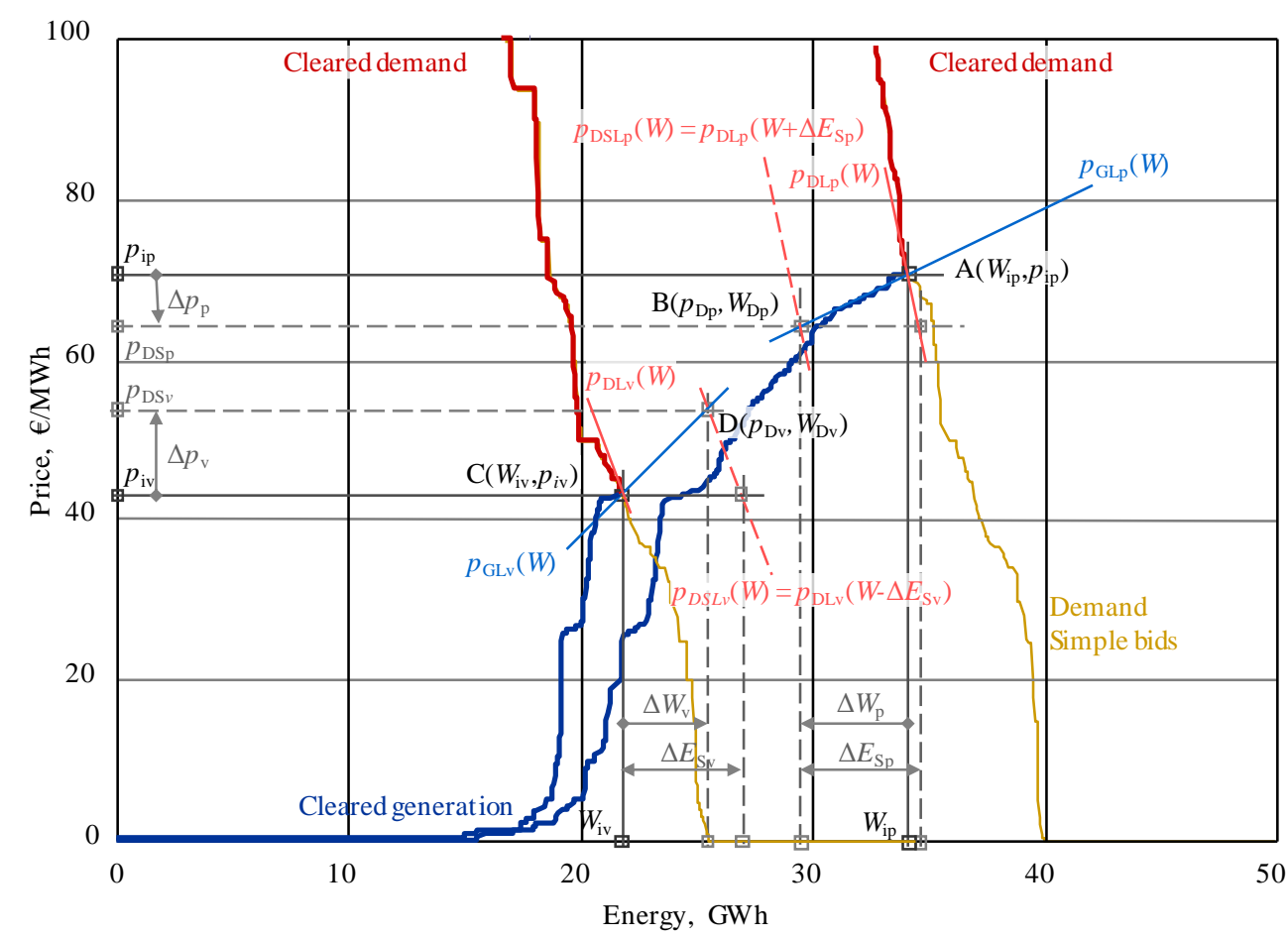

Fig. 2. Merit-order generation, $p_{\mathrm{G}}(\mathrm{W})$, and demand, $p_{\mathrm{D}}(\mathrm{W})$, curves for a valley $(04: 00 \mathrm{~h})$ and peak $(20: 00 \mathrm{~h})$ hours on a working day in winter corresponding to the Iberian market [16]. Changes in demand curves and market clearing points due to load-shifting.

At off-peak hours, the increase in the same amount of energy, $\Delta E_{\mathrm{Dv}}$, at very high marginal price, leads to the integration of new generation offers with higher marginal prices due to the shift to the right of the demand curve. The linear approximation of this new demand curve, $p_{\text {DSv }}(\mathrm{W})$, is shown in Fig. 2 as a line parallel to the primitive demand curve for the off-peak hour:

$$
p_{\mathrm{DSv}}(W) \approx p_{\mathrm{DLv}}\left(W-\Delta E_{\mathrm{Dv}}\right)=p_{\mathrm{iv}}+m_{\mathrm{Dv}}\left(W-W_{\mathrm{iv}}-\Delta E_{\mathrm{Dv}}\right)=p_{\mathrm{DSiv}}+m_{\mathrm{Dv}} W,(13
$$

where

$$
p_{\mathrm{DSiv}}=p_{\mathrm{iv}}-m_{\mathrm{Dv}}\left(W_{\mathrm{iv}}-\Delta E_{\mathrm{Dv}}\right)
$$

Table 3 summarizes the expressions and results corresponding to the variation of the traded energy, clearing price, and cost of the traded energy derived from the curtailment of a number of demand bids, $\Delta E_{\mathrm{Dp}}$, offered at maximum price, at a peak hour and the increment in the amount of demand bids, $\Delta E_{\mathrm{Dv}}$, offered at maximum price, at an off-peak hour. The results are based again on the illustrative example in Table 1, considering $\Delta E_{\mathrm{Dv}}=\Delta E_{\mathrm{Dp}}=\Delta E_{\mathrm{D}}$. 
TABLE 3. LINEARIZED MARKET MODEL ESTIMATION OF THE

VARIATION OF THE TRADED ENERGY, PRICE AND COST DERIVED FROM THE

LOAD-SHIFTING OF CERTAIN AMOUNT OF ENERGY BIDS, $\Delta E_{\mathrm{DP}}$, AND, $\Delta E_{\mathrm{Dv}}$, RESPECTIVELY

\begin{tabular}{|c|c|c|}
\hline & Peak hour & 20:00 h \\
\hline \multirow{2}{*}{$\begin{array}{l}\text { Relative variation of the } \\
\text { traded energy }\end{array}$} & $\frac{\Delta W\left(\Delta E_{\mathrm{Dp}}\right)}{2} \approx \frac{m_{\mathrm{Dp}}}{<0}$ & \multirow[t]{2}{*}{-0.91} \\
\hline & $\Delta E_{\mathrm{Dp}} \quad m_{\mathrm{Gp}}-m_{\mathrm{Dp}}$ & \\
\hline \multirow{2}{*}{$\begin{array}{l}\text { Relative variation of the } \\
\text { clearing price, } € / \mathrm{MWh}^{2}\end{array}$} & $\underline{\Delta p_{\mathrm{DLS}}\left(\Delta E_{\mathrm{Dp}}\right)} \approx \frac{m_{\mathrm{Gp}} m_{\mathrm{Dp}}}{<0}$ & \multirow[t]{2}{*}{$-1.27 \cdot 10^{-3}$} \\
\hline & $\Delta E_{\mathrm{Dp}} \sim m_{\mathrm{Gp}}-m_{\mathrm{Dp}}$ & \\
\hline \multirow{3}{*}{$\begin{array}{l}\text { Relative variation of the } \\
\text { cost of the energy traded, } \\
€ / \mathrm{MWh}\end{array}$} & $\Delta C\left(\Delta E_{\mathrm{Dp}}\right) \sim\left(W_{\mathrm{ip}} m_{\mathrm{Gp}}+p_{\mathrm{ip}}\right) m_{\mathrm{Dp}}$ & \multirow[t]{2}{*}{-107.68} \\
\hline & $\Delta E_{\mathrm{Dp}} \quad m_{\mathrm{Gp}}-m_{\mathrm{Dp}}$ & \\
\hline & Off-peak hour & 04:00 h \\
\hline \multirow{2}{*}{$\begin{array}{l}\text { Relative variation of the } \\
\text { traded energy }\end{array}$} & $\underline{\Delta W\left(\Delta E_{\mathrm{Dv}}\right)} \approx-\frac{m_{\mathrm{Dv}}}{->0}$ & \multirow{2}{*}{0.71} \\
\hline & $m_{\mathrm{Gv}}-m_{\mathrm{Dv}}$ & \\
\hline \multirow{2}{*}{$\begin{array}{l}\text { Relative variation of the } \\
\text { clearing price, } € / \mathrm{MWh}^{2}\end{array}$} & $\underline{\Delta p\left(\Delta E_{\mathrm{Dv}}\right)} \approx-\frac{m_{\mathrm{Gv}} m_{\mathrm{Dv}}}{>0}$ & \multirow{2}{*}{$2.07 \cdot 10^{-3}$} \\
\hline & $\Delta E_{\mathrm{Dv}} \quad m_{\mathrm{Gv}}-m_{\mathrm{Dv}}$ & \\
\hline \multirow{2}{*}{$\begin{array}{l}\text { Relative variation of the } \\
\text { cost of the energy traded, } \\
€ / \mathrm{MWh}\end{array}$} & 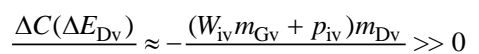 & \multirow{2}{*}{77.75} \\
\hline & $m_{\mathrm{Gv}}-m_{\mathrm{Dv}}$ & \\
\hline
\end{tabular}

Comparison of peak vs. off-peak

Relative variation of the traded energy

$\left|\frac{\Delta W\left(\Delta E_{\mathrm{Dv}}\right)}{\Delta W\left(\Delta E_{\mathrm{Dp}}\right)}\right| \approx\left|\frac{m_{\mathrm{Dv}}}{m_{\mathrm{Gv}}-m_{\mathrm{Dv}}} \frac{m_{\mathrm{Gp}}-m_{\mathrm{Dp}}}{m_{\mathrm{Dp}}}\right|<1$

Relative variation of the sum of traded energies

$\frac{\Delta W\left(\Delta E_{\mathrm{Dv}}\right)-\Delta W\left(\Delta E_{\mathrm{Dp}}\right)}{\left|\Delta E_{\mathrm{D}}\right|} \approx-\frac{m_{\mathrm{Dv}}}{m_{\mathrm{Gv}}-m_{\mathrm{Dv}}}+\frac{m_{\mathrm{Dp}}}{m_{\mathrm{Gp}}-m_{\mathrm{Dp}}}<0$

Relative variation of the clearing price

$$
\left|\frac{\Delta p_{\mathrm{D}}\left(\Delta E_{\mathrm{Dv}}\right)}{\Delta p_{\mathrm{D}}\left(\Delta E_{\mathrm{Dp}}\right)}\right| \approx\left|\frac{m_{\mathrm{Gv}} m_{\mathrm{Dv}}}{m_{\mathrm{Gv}}-m_{\mathrm{Dv}}} \frac{m_{\mathrm{Gp}}-m_{\mathrm{Dp}}}{m_{\mathrm{Gp}} m_{\mathrm{Dp}}}\right|>1
$$

Relative variation of the sum of clearing prices, $€ / \mathrm{MWh}^{2}$

$$
\frac{\Delta p\left(\Delta E_{\mathrm{Dv}}\right)+\Delta p\left(\Delta E_{\mathrm{Dp}}\right)}{\left|\Delta E_{\mathrm{D}}\right|} \approx-\frac{m_{\mathrm{Gv}} m_{\mathrm{Dv}}}{m_{\mathrm{Gv}}-m_{\mathrm{Dv}}}+\frac{m_{\mathrm{Gp}} m_{\mathrm{Dp}}}{m_{\mathrm{Gp}}-m_{\mathrm{Dp}}}>0
$$

Relative variation of the cost of the traded energy

$$
\left|\frac{\Delta C\left(\Delta E_{\mathrm{Dv}}\right)}{\Delta C\left(\Delta E_{\mathrm{Dp}}\right)}\right| \approx\left|\frac{m_{\mathrm{Gp}}-m_{\mathrm{Dp}}}{m_{\mathrm{Gv}}-m_{\mathrm{Dv}}} \frac{\left(W_{\mathrm{iv}} m_{\mathrm{Gv}}+p_{\mathrm{iv}}\right) m_{\mathrm{Dv}}}{\left(W_{\mathrm{ip}} m_{\mathrm{Gp}}+p_{\mathrm{ip}}\right) m_{\mathrm{Dp}}}\right|<1
$$

Relative variation of the sum of the cost of the traded energies, $€ / \mathrm{MWh}$

$$
\frac{\Delta C\left(\Delta E_{\mathrm{Dv}}\right)+\Delta C\left(\Delta E_{\mathrm{Dp}}\right)}{\left|\Delta E_{\mathrm{D}}\right|} \approx-\frac{\left(W_{\mathrm{iv}} m_{\mathrm{Gv}}+p_{\mathrm{iv}}\right) m_{\mathrm{Dv}}}{m_{\mathrm{Gv}}-m_{\mathrm{Dv}}}+\frac{\left(W_{\mathrm{ip}} m_{\mathrm{Gp}}+p_{\mathrm{ip}}\right) m_{\mathrm{Dp}}}{m_{\mathrm{Gp}}-m_{\mathrm{Dp}}}<0
$$

From the qualitative linear analysis, considering $\Delta E_{\mathrm{Dv}}=\Delta E_{\mathrm{Dp}}=\Delta E_{\mathrm{D}}$, the following hypotheses can be established:

- The load-shifting reduces the traded energy at peak hours and increases it at off-peak hours. The increase in the traded energy at off-peak hours, however, remains less than the reduction at peak hours. Consequently, each complete cycle of load-shifting yields a net reduction in cleared energy. This unexpected effect, by which each cycle of load-shifting leads to a net reduction in the traded energy in the market, is a valuable observation that has gone unnoticed till now; 
- The load-shifting reduces the price at peak hours and increases it at off-peak hours; however, the increase at the off-peak hour is somewhat higher than the reduction at the peak hour. Therefore, each load-shifting cycle produces an increase in the arithmetic mean of the price;

- Although the reduction of the number of energy purchase bids at the peak hour is equal to the increase of the number of purchase bids at the off-peak hour $\left(\Delta E_{\mathrm{Dv}}=\Delta E_{\mathrm{Dp}}\right)$, the total traded energy in a cycle is reduced as a result of the effect of the generation slope and, to a lesser extent, of the demand slope. Therefore, every complete cycle of load-shifting leads to a reduction in the cost of the energy traded in the market.

Consequently, each complete cycle of load-shifting yields a net reduction in cleared energy. The unnoticed net reduction of the traded energy in the market that results from the cycle of load-shifting can find an explanation in the slopes of the generation and demand curves. More precisely in the apparent clock rotation of the slopes of the curves from the valley to the peak that can be observed in Fig. 2. Due to that rotation, the reduction of cleared energy in the peak results greater than the increase in the valley. All this, despite the fact that the amount of purchase bid withdrawn at the peak is the same as the amount of demand bid increased in the valley.

\section{Materials AND Methods}

In order to make the results obtained as realistic as possible, the new market scenarios considered in this work are all developed from real situations of the Iberian energy market. Accordingly, the reference information for the scenarios is that provided by the hourly meritorder generation and demand curves for 2015, retrieved from the historical data archive of the Iberian Market Operator (OMIE). That implies 8.760 hourly clearing prices and traded energy with hundreds of production and demand bids taking part in each hourly market. The huge amount of day-ahead markets (vast number of bids) handled for each scenario forced some simplification to be included in the complex clearing rules of the Market Operator. As a consequence, a simplified procedure similar to that used by the Market Operator (OMIE) has been used in order to perform a quantitative analysis of the scenarios that are as realistic as possible.

Once the market information is conveniently processed, a set of empirical-based scenarios with load-shifting and renewables have been generated. This work aims to quantify and compare the main effects on the Spanish/Iberian market. Thus, for each new scenario analysed, new hourly curves of generation and demand are developed, in a three-step sequence [13], [14]:

- First, locating the offers corresponding to the type of agent under interest (renewable generation, for example), in the originally cleared generation and demand curves and modified them (quantity of energy and/or price), taking into account the appropriate characteristics of the new scenario that has been considered;

- Second, preparing the production and demand curves corresponding to the new scenario, rearranging the generation bids by growing price and the demand bids by decreasing price;

- Third, complete the new generation curve with the simple bid generation curve.

Finally, the matching point of the new scenario is determined as the crossing point of the new completed generation and demand curves. For example, Fig. 3 shows the initial market situation with the actual generation and demand curves retrieved from the Market Operator (OMIE). For a scenario that considers the integration of an additional supply bid of renewable 
production, $\Delta E_{R}$, offered at zero price, the new production and demand curve are prepared as follows:

First, the additional supply bid of renewable production, $\Delta E_{\mathrm{R}}$, is introduced in the initial flat region of the cleared generation curve, $p_{\mathrm{G}}(\mathrm{W})$, since the new renewable generation is offered at zero price. The integration of this new bid leads to a right shift of the cleared generation curve, $p_{\mathrm{GR}}(\mathrm{W})=p_{\mathrm{G}}\left(W-\Delta E_{\mathrm{R}}\right)$, from the insertion point on $\left(\forall W \leq W_{\mathrm{i}}+\Delta E_{\mathrm{R}}\right)$. Now, when needed, the generation curve is completed with the simple generation curve, $p_{\mathrm{Gs}}(\mathrm{W})$, from the initial clearing point on, $\mathrm{A}\left(W_{\mathrm{i}}, p_{\mathrm{i}}\right)$. Accordingly, the new completed generation curve results: $p_{\mathrm{GRc}}(\mathrm{W})=\left\{p_{\mathrm{G}}\left(W-\Delta E_{\mathrm{R}}\right) \forall W \leq W_{i}+\Delta E_{\mathrm{R}}\right\} \subset\left\{p_{\mathrm{Gs}}\left(W+W^{\prime}{ }_{\mathrm{is}}-W_{\mathrm{i}}-\Delta E_{\mathrm{R}}\right)\right.$ $\left.\forall W>W_{\mathrm{i}}+\Delta E_{\mathrm{R}}\right\}$, as can be seen in Fig. 3 .

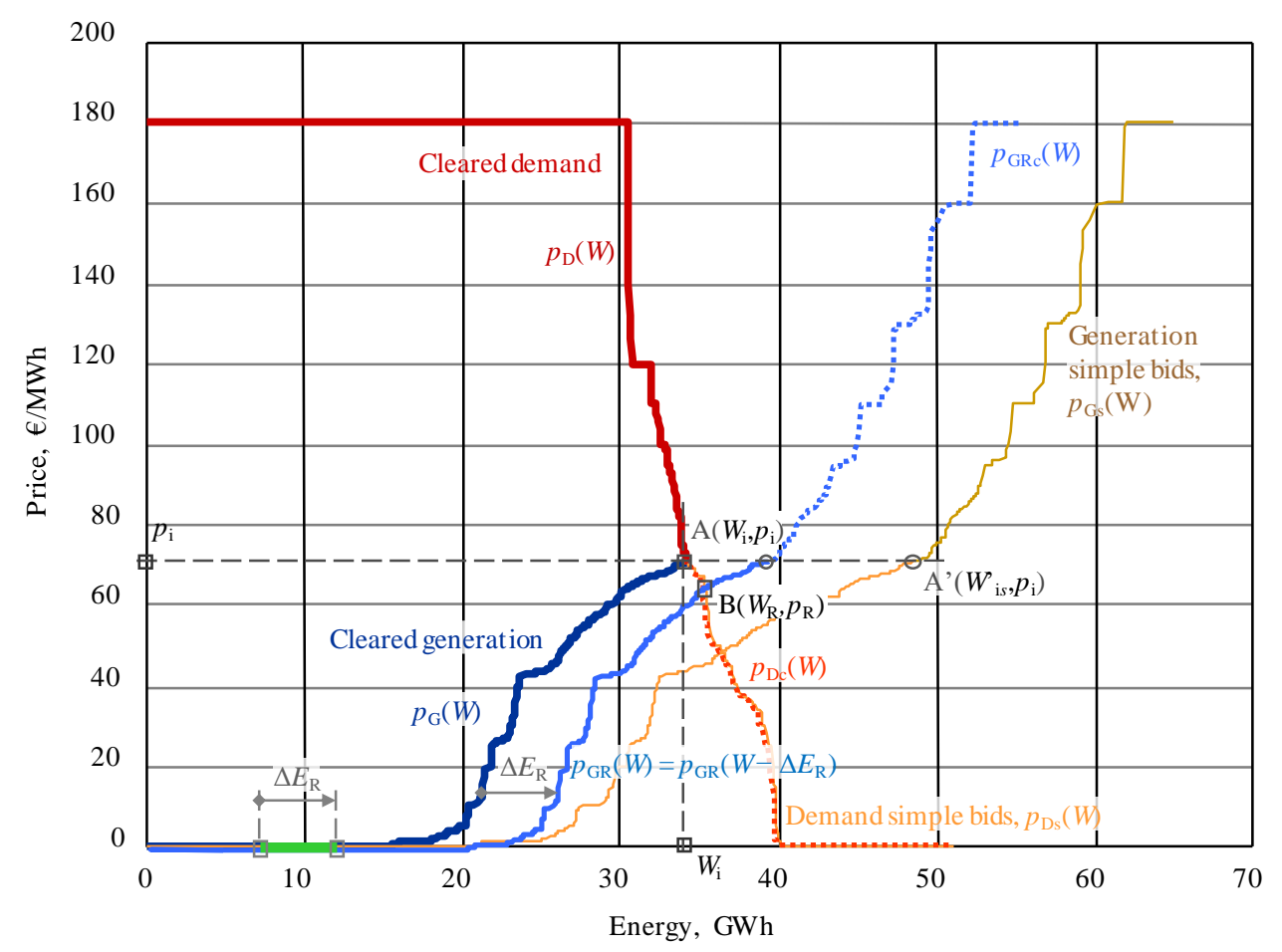

Fig. 3. Merit-order generation, $p_{\mathrm{G}}(\mathrm{W})$, and demand, $p_{\mathrm{D}}(\mathrm{W})$, curves for a peak hour on a working day in winter corresponding to the Iberian market [13]. Changes in the generation curve and market clearing point due to the integration of an amount of renewable bids, $\Delta E_{\mathrm{R}}$, at very low price.

For what refers to the demand curve, the methodology is more straightforward. Since only simple bids are allowed, the completed demand curve coincides with the simple demand curve, $p_{\text {Dc }}(\mathrm{W})=\left\{p_{\text {Ds }}(W) \forall W\right\}$, as can also be seen in Fig. 3 .

Finally, the crossing point of the new completed curves, $p_{\mathrm{GRc}}(\mathrm{W})=p_{\mathrm{Dc}}(\mathrm{W})$, leads to the new clearing point, $\mathrm{B}\left(W_{\mathrm{R}}, p_{\mathrm{R}}\right)$ in Fig. 3 , corresponding to this scenario with integration of renewables.

As can be observed, in this case, only the demand curve needed to be completed since the new clearing point, $\mathrm{B}\left(W_{\mathrm{R}}, p_{\mathrm{R}}\right)$, could has been determined with the right-shifted generation curve, equalling $p_{\mathrm{GR}}(\mathrm{W})=p_{\mathrm{Dc}}(\mathrm{W})$. 
For the load-shifting scenarios, an amount of energy purchase bids, $\Delta E_{D}$, offered at the maximum price, is curtailed at peak hours and increased at valley hours. The corresponding completed demand curves are obtained by shifting the simple demand curve, $p_{\text {Dc }}(\mathrm{W})=p_{\text {Ds }}\left(W \pm \Delta E_{\mathrm{R}}\right)$, rightwards (valley hours) or leftwards (peak hours). In this case, the completed generation curve is composed joining the cleared generation curve and the simple generation curve, from the initial clearing point on, $p_{\mathrm{Gc}}(W)=\left\{p_{\mathrm{G}}(W) \forall W \leq W_{\mathrm{i}}\right\} \subset\left\{p_{\mathrm{Gs}}\left(W+W^{\prime}{ }_{\mathrm{is}}-W_{\mathrm{i}}\right) \forall W>W_{\mathrm{i}}\right\}$.

\section{RESUlTS AND DisCUSSION}

As mentioned, the base information for the scenarios considered in this work is that provided by the hourly merit-order generation and demand curves for 2015, retrieved from the historical data archive of the Iberian Market Operator (OMIE). From this Base Case, three new loads-shifting scenarios have been analysed in this work. In these scenarios, it is considered that equivalent energy demand bids of $\Delta E_{\mathrm{D} 1}=0.59 \mathrm{TWh} / \mathrm{year}$, $\Delta E_{\mathrm{D} 2}=1.46 \mathrm{TWh} /$ year, and $\Delta E_{\mathrm{D} 3}=2.93 \mathrm{TWh} /$ year (at maximum price) are daily shifted from the three peak hours to three off-peak hours. These energy amounts correspond to $2 \%, 5 \%$ and $10 \%$ of the peak hourly demand of domestic consumers, respectively.

Table 4 summarises the results obtained for the scenarios of load-shifting, in which it can be verified that the annual values of the traded energy and the annual cost of the traded energy in the market remain lower than the corresponding values of the Base Case, while the arithmetic mean of the price grows.

In general terms, the following can be observed:

- Energy. For all the load-shifting scenarios considered, it can be observed that there is a slight reduction in the total energy traded. This, in principle, unexpected energy-saving side-effect occurs because the reduction in energy that takes place during peak hours is greater than the associated increase that occurs in off-peak hours;

- Price. For all the scenarios considered, there is an increase in the arithmetic mean of the price, as expected;

- Cost. The load-shifting brings a reduction of the annual cost of the energy negotiated in the market for all the scenarios considered. The cost reduction is approximately proportional to the amount of energy bids shifted from peak to off-peak, as was anticipated with the linear qualitative model.

Since the percentage reduction of the cost of the traded energy is higher than the corresponding to the traded energy, the mean price $(C / W)$ is also lower than for the Base Case. These three observations all confirm the predictions made with the linear qualitative analysis. 
Table 4. Annual Traded Energy, Average Hourly Price, And AnNual COST OF THE TRADED ENERGY FOR THE SCENARIOS OF LOAD-SHIFTING CONSIDERED

\begin{tabular}{|c|c|c|c|c|c|c|}
\hline \multirow{3}{*}{$\begin{array}{l}2015 \\
\text { Base case, TWh }\end{array}$} & \multicolumn{6}{|c|}{ Annual traded energy } \\
\hline & \multicolumn{2}{|c|}{$\begin{array}{l}\text { Scenario D1 } \\
\Delta E=2 \% \text { Load-shifting } \\
(0.59 \mathrm{TWh} / \text { year, } 3 \mathrm{~h})\end{array}$} & \multicolumn{2}{|c|}{$\begin{array}{l}\text { Scenario D2 } \\
\Delta E=5 \% \text { Load-shifting } \\
(1.46 \mathrm{TWh} / \text { year, } 3 \mathrm{~h})\end{array}$} & \multicolumn{2}{|c|}{$\begin{array}{l}\text { Scenario D3 } \\
\Delta E=10 \% \text { Load-shifting } \\
(2.93 \mathrm{TWh} / \text { year, } 3 \mathrm{~h})\end{array}$} \\
\hline & TWh & $\%$ & TWh & $\%$ & TWh & $\%$ \\
\hline \multirow[t]{2}{*}{226.06} & 225.91 & -0.07 & 225.72 & -0.15 & 225.51 & -0.24 \\
\hline & \multicolumn{6}{|c|}{ Mean hourly price } \\
\hline Base case, $€ /$ MWh & $€ / \mathrm{MWh}$ & $\%$ & $€ / \mathrm{MWh}$ & $\%$ & $€ / \mathrm{MWh}$ & $\%$ \\
\hline \multirow[t]{2}{*}{50.32} & 50.37 & 0.09 & 50.40 & 0.16 & 50.42 & 0.19 \\
\hline & \multicolumn{6}{|c|}{ Annual cost of energy traded on the market } \\
\hline Base case, $\mathrm{M€}$ & $\mathrm{M} €$ & $\%$ & $\mathrm{M} €$ & $\%$ & $\mathrm{M} €$ & $\%$ \\
\hline 11662 & 11646 & -0.14 & 11621 & -0.35 & 11584 & -0.67 \\
\hline
\end{tabular}

It should be remarked that the unexpected energy-saving side-effect of the load-shifting is due to the unintended "collaboration" of two kinds of consumers. On the one hand, there are the numerous (non-flexible) consumers fully dependent on the grid, those which are willing to pay even the maximum price. Accordingly, their purchase bids are placed at the initial flat region, with maximum price, of the demand curve. These kinds of consumers, such as the domestic consumers, are willing to shift part of their load from the peak to the valley, to save some money in their energy bills. On the other hand, there is a slightly small number of flexible industrial consumers which only purchase in the wholesale market when the price of the energy is lower than their own cost of production or substitution. Hence, flexible consumers only send purchase bids with medium prices and their bids are placed in the descending region of the demand curve. This is the region where the clearing price takes place.

In short, non-flexible consumers carry out the load displacement effort, and flexible consumers are those who allow the benefits of the load-shifting to be materialized.

\section{Conclusions}

The high and growing cost of energy, the interest of consumers in reducing their energy bills, and the promotion of load-shifting programs by policy-makers are expected to work as drivers for a reduction of the cost of the energy traded on the wholesale market.

This work has introduced a simplified market model, based on the linearization of the wholesale market around the clearing point, in order to describe and quantify the merit-order effect of load-shifting. This simplified tool has also been used to compare the merit-order effect of load-shifting and renewables.

A set of heuristic-based load-shifting scenarios have subsequently been developed and analysed to estimate their main quantitative effects on the market.

The results for 2015 show that, on average, for each TWh of demand bid that is daily shifted from the three peak hours to the three off-peak hours:

- The total traded energy is reduced by $0.23 \mathrm{TWh}$;

- The arithmetic mean of the price is increased by $0.055 € / \mathrm{MWh}$;

- The total cost of annual energy negotiated in the market is reduced by $28.08 \mathrm{M} €$. 
Both the qualitative linear analysis and the quantitative results fully confirm that load-shifting scenarios exhibit similar economic performance and environmental sustainability to that of the integration of renewables. Accordingly, all these results prove the existence a "merit-order effect of load-shifting", similar to well-known the merit-order effect of the renewables.

\section{ACKNOWLEDGEMENT}

This work was supported by the Spanish MEC - Ministerio de Economía y Competitividad (Ministry of Economy and Competitiveness) under grant ENE2016-77650-R.

\section{REFERENCES}

[1] Sensfuss M., Ragwitz M. The merit-order effect: A detailed analysis of the price effect of renewable electricity generation on spot market prices in Germany. Energy Policy 2008:36(8):3086-3094. https://doi.org/10.1016/j.enpol.2008.03.035

[2] Saenz de Miera G., del Rio Gonzalez P., Vizcaino I. Analysing the impact of renewable electricity support schemes on power prices: The case of wind electricity in Spain. Energy Policy 2008:36(9):3345-3359. https://doi.org/10.1016/j.enpol.2008.04.022

[3] Burgos Payan M., et al. Costs and benefits of the renewable production of electricity in Spain. Energy Policy 2013:56:259-270. https://doi.org/10.1016/j.enpol.2012.12.047

[4] Roldan-Fernandez J. M., et al. Impact of renewable generation in the Spanish Electricity Market. Presented at the 11th International Conference on the European Energy Market (EEM), Krakow, Poland, 2014 http://dx.doi.org/10.1109/EEM.2014.6861239

[5] Darby S. The effectiveness of feedback on energy consumption. A review for DEFRA of literature on metering, billing and direct displays. Oxford: University of Oxford, Environmental Change Institute, 2006. [Online]. [Accessed: 26.06.2019]. Available: http://www.eci.ox.ac.uk/research/energy/downloads/smart-metering-report.pdf

[6] Porubova J., Bazbauers G. Analysis of Long-Term Plan for Energy Supply System for Latvia that is 100\% Based on the Use of Local Energy Resources. Environmental and Climate Technologies 2010:4(1):82-90. https://doi.org/10.2478/v10145-010-0022-7

[7] Darby S. Smart Metering: What Potential for Householder Engagement? Building Research and Information 2010:38(5):442-457. http://dx.doi.org/10.1080/09613218.2010.492660

[8] Faruqui A., Sergici S. Household response to dynamic pricing of electricity: a Survey of 15 experiments. Journal of Regulatory Economy 2010:38(2):193-225. http://dx.doi.org/10.1007/s11149-010-9127-y

[9] Faruqui A., Sergici S., Sharif A. The impact of informational feedback on energy consumption - A survey of the experimental evidence. Energy 2010:35(4):1598-1608. http://dx.doi.org/10.1016/j.energy.2009.07.042

[10] Vine D., Buys L., Morris P. The Effectiveness of Energy Feedback for Conservation and Peak Demand: A Literature Review. Open Journal of Energy Efficiency 2013:2(1):7-15. http://dx.doi.org/10.4236/ojee.2013.21002

[11] Vigants H., Blumberga D., Veidenbergs I. Demand Side Management in Pellet Production: Internal and External Factors. Environmental and Climate Technologies 2014:14(1):30-35. https://doi.org/10.1515/rtuect-2014-0011

[12] Bariss U., Bazbauers G., Blumberga A., Blumberga D. System Dynamics Modeling of Households' Electricity Consumption and Cost-Income Ratio: a Case Study of Latvia. Environmental and Climate Technologies 2017:20(1):3650. https://doi.org/10.1515/rtuect-2017-0009

[13] Roldan-Fernandez J. M., Burgos Payan M., Riquelme Santos J. M., Trigo Garcia A. L. The voluntary price for the small consumer: Real-time pricing in Spain. Energy Policy 2017:102:41-51. http://dx.doi.org/10.1016/j.enpol.2016.11.040

[14] Roldan-Fernandez J. M., Burgos Payan M., Riquelme Santos J. M., Trigo Garcia A. L. Renewable generation versus demand-side management. A comparison for the Spanish market. Energy Policy 2016:96:458-470. http://dx.doi.org/10.1016/i.enpol.2016.06.014

[15] OMIE - Operador del Mercado Iberico de la Electricidad (Market Operator of the Iberian Electricity Market), 2014. Daily and Intraday Electricity Market Operating Rules. [Online]. [Accessed: 26.06.2019]. Available: http://www.omie.es/files/20140509_reglas_v11_ingles.pdf

[16] OMIE - Operador del Mercado Iberico de la Electricidad (Market Operator of the Iberian Electricity Market). Market Results [Online]. [Accessed 26.06.2019]. Available: http://www.omie.es/files/flash/ResultadosMercado.swf 


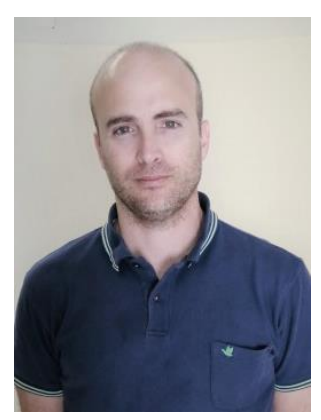

Juan M. Roldan-Fernandez, Dr Assistant Professor at the Universidad de Sevilla, Spain. He holds a Master's Degree in Industrial Engineering (2003) and Electric Power Systems (2011) from the Universidad de Sevilla. He subsequently completed a PhD about Renewables and Electricity Markets (2017).

Dr assistant professor at the Universidad de Sevilla (Spain). Before 2011, Dr Juan M. Roldan has worked as Electrical Engineer in several electrical companies designing and developing substations and renewable energy projects. After that he has been part of academic staff of the Department of Electrical Engineering, in the Universidad de Sevilla. The main research area is renewable energy resources, energy efficiency and electricity markets.

ORCID iD: https://orcid.org/0000-0002-3811-1078

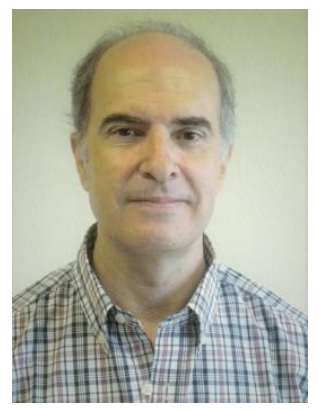

Manuel Burgos-Payan, Dr Professor at the Universidad de Sevilla, Spain. He holds a Master's Degree in Industrial Engineering (1985) and a PhD degree (1994) both from the Universidad de Sevilla.

Dr Burgos-Payán has been part of academic staff of the Department of Electrical Engineering, in the Universidad de Sevilla, since 1983. The main research area is electrical machines, renewable energy, energy efficiency and electricity markets.

ORCID iD: https://orcid.org/0000-0001-8072-1593

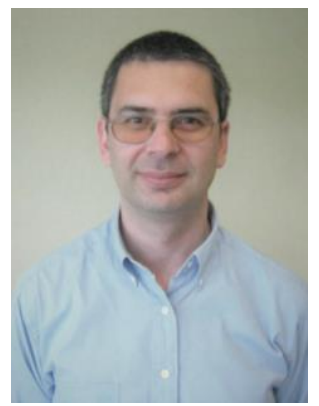

Jesus M. Riquelme-Santos, Dr Professor at the Universidad de Sevilla, Spain. He holds a Master's Degree in Industrial Engineering (1993) and a PhD degree (1999) both from the Universidad de Sevilla.

Dr Riquelme-Santos has been part of academic staff of the Department of Electrical Engineering, in the Universidad de Sevilla, since 1994. He has been associate professor in 2002 and full professor in 2008. He was also Head of the Electrical Engineering Department (University of Sevilla). Actually, he serves as Director of Master Degree in Electrical Power System. He is responsible and participant in about 80 research projects financed by the Spanish Ministry of Research, by Andalucía Government and foreign companies and universities concerning security power systems, optimum offer to the electrical market, distributed generation and wind farm optimum design. His main research topics are active power optimization and control, power system analysis power quality, decision support tools for power producers in a competitive electricity market and renewable energy.

In 2005 he was awarded with the Award of Energy "City of Seville", modality of "Energetic Investigation", granted by the Agency of the Energy of the Town Hall of Seville. April, 2005. In 2007 he was also awarded with the NOVARE Prize, granted by ENDESA, in the category of Intelligent Networks of Distribution.

ORCID iD: https://orcid.org/0000-0001-6280-6796 